\title{
Experimental investigation of process parameters during graphitization of catalytic coke
}

\author{
Kobra Pourabdollah ${ }^{1} \cdot$ Masoud Samadian Zakaria $^{2}$. \\ Seyed Mohammad Mir Najafizadeh ${ }^{2} \cdot$ Fatemeh Motaghedi $^{1}$
}

Received: 3 June 2019/Revised: 29 August 2019/ Accepted: 14 October 2019/Published online: 11 November 2019

(C) The Author(s) 2019

\begin{abstract}
The aim of this project is studying the effect of thermal operation parameters on the graphitization of selfdiffused ethane-based catalytic coke. The novelty of this study refers to self-diffused metals that had given unique properties to the catalytic coke and had improved the graphitization degree at low temperatures. The main feature of this research is presenting a remarkable energy saving approach that uses low-cost installations for production of graphitized carbon. The experiments were performed in two steps including preparation of self-diffused ethane-based catalytic coke and then low-temperature graphitization of coke samples below $1500{ }^{\circ} \mathrm{C}$. Characteristic tests were performed by determination of electrical resistivity and XRD pattern of graphitized samples including graphitization degree, aromaticity, coke rank, number of carbon rings, graphene thickness and length. The results revealed that the blanket atmosphere, final temperature and exposure time had the greatest impact on the aforementioned criteria, while the role of thermal ramp and sulfur content of catalytic coke was negligible. The electrical resistivity tests on the graphitized sample showed how the electrical resistivity of graphitized samples is a function of graphitization degree.
\end{abstract}

Keywords Graphite $\cdot$ Catalytic coke $\cdot$ Self-diffusion $\cdot$ Desulfurization

\section{Introduction}

Solid carbons, cokes and chars consist of randomly arranged crystalline-phases that are imperfect and distributed in the solid matrix (Wissler 2006). Synthetic cokes (Pourabdollah 2018a) exhibit the properties of metals including electrical and thermal conductivity and of non-metals including lubricity, high thermal resistance and inertness (Feng et al. 2003) and are used in cathodic wells and oil wells (Pourabdollah 2017a, 2018b), batteries (Pourabdollah 2017b) and furnaces.

Kobra Pourabdollah

Pourabdollah@ccerci.ac.ir

1 Chemistry and Chemical Engineering Research Center of Iran, Tehran, Iran

2 Department of Research and Technology, Tehran Province Gas Company, Tehran, Iran
Catalytic graphitization of coal and hydrocarbons by transition metals has been used for encapsulation, formation of fibers and carbon nanotubes (De Jong and Geus 2000; Bokhonov and Korchagin 2002; Helveg et al. 2004). When the solid carbon is produced from a gas phase, the catalytic graphitization can intensify the reaction by forming a thin film of amorphous carbon on the catalyst particles (Anton 2005, 2008). Using nickel (Anton 2009) and iron (Bokhonov and Korchagin 2002) catalyzers, the graphitization was conducted with encapsulation of metal particles by graphite layers.

Interaction of metallic catalyzers (such as $\mathrm{La}, \mathrm{Ce}$ and $\mathrm{Pr}$ ) with coal, coke and graphite materials is based upon the chemical addition of fine powders of metals followed by heating and proceeding the reaction (Wang et al. 2016). On the other hand, the diffusion of some elements in the graphite matrix has been investigated and it was revealed that boron (Hennig 1965), argon and helium (SHIGENO et al. 1988), uranium (Loch et al. 1956), cesium (Carter et al. 2015) and iron (Stoneham 1979) diffuse in the coke matrix 
at elevated temperature, leading to the catalysis of the graphitization reaction.

Feng et al. (2003) investigated the crystallite structure of several coke samples during $\mathrm{CO}_{2}$ and air gasification. The thermal annealing of several coke samples were applied and followed by studying the evolution of carbon structure in the coke matrix and the results revealed a linear correlation between the annealing temperature and the stack height $\left(\mathrm{L}_{002}\right)$ of carbon crystallite (Gupta et al. 2005). The carbon structure in the coke matrix, which has a non-graphitic and turbostratic scaffold, can capture inorganic impurities such as metals. The dimensions of graphiticcrystallite in the coke matrix is characterized by the interlayer spacing ( $\mathrm{c} / 2=$ half the hexagonal lattice c-axis), the thickness of hexagonal packing $\left(\mathrm{L}_{\mathrm{c}}=\right.$ crystallite dimension in the c-axis direction) (Feret 1998; Lu et al. 2001; Sonibare et al. 2010; Mollick et al. 2015), the spread of carbon basal plane $\left(\mathrm{L}_{\mathrm{a}}=\right.$ crystallite dimension in the a-axis direction) (Sonibare et al. 2010; Mollick et al. 2015), aromaticity (Sonibare et al. 2010; Odeh 2015), coke rank (Yoshizawa et al. 2001; Sonibare et al. 2010), graphitation degree (Mollick et al. 2015) and number of carbon rings (Belenkov 2001) and grapheme layers (Mollick et al. 2015), which are determined from X-ray diffraction (XRD) patterns. Not only the bond strengths are not fixed along the crystallographic directions, but also a variety of voids, defects and cross-links are present in the coke matrix. Therefore, various reaction rates in the coke matrix show an anisotropic character and have a directional nature ( $\mathrm{Li}$ et al. 2014).

The first aim of this study is to produce a catalytic coke from ethane feed at temperature $850{ }^{\circ} \mathrm{C}$ range along with the self-diffusion of some transition metals ( $\mathrm{Fe}, \mathrm{Ni}$ and $\mathrm{Cr}$ ) as catalyzers of the upcoming reaction. The second aim is to optimize the low-temperature $\left(850-1470{ }^{\circ} \mathrm{C}\right)$ catalytic graphitization reaction based upon the aforementioned selfdiffused catalyzers. The third aim is to characterize the self-diffused catalytic graphitization of coke by XRD algorithms. The micro-texture terminology and the classification of graphite samples vary in different countries; hence, a reference method was developed for characterization of graphite scaffolds and measurement of their electrical resistance.

\section{Experimental methods}

The experiments have been conducted in two sections including preparation of the catalytic coke from ethane feed in a gas cracker furnace and graphitization of the catalytic coke in a calcination kiln.

\subsection{Preparation of the catalytic coke}

A cylindrical self-diffused catalytic coke was prepared inside a tubular reactor located in the hot section of gascracker furnace. The reactor was heated by a gas fuel stream from bottom $\left(1175^{\circ} \mathrm{C}\right)$ to top $\left(157^{\circ} \mathrm{C}\right)$ sections of furnace. In order to improve the thermal stability of tubular reactor, their optimum chemical composition was $\mathrm{Fe}, \mathrm{Ni}$, $\mathrm{Cr}$ and $\mathrm{Nb}(37: 35: 25: 3 \mathrm{wt} \%)$, respectively. At the initial stage of the cracking process, a sulfidation stage is performed in order to cover the inside surfaces of tubular reactor and decrease the adhesion tendency of the catalytic coke. Therefore, dimethyl disulfide (DMDS) was injected into the stream of dilution steam for sulfidation at $1 \mathrm{~h}$ and $101 \mathrm{kPa}$. During the sulfidation, DMDS concentration in dilution steam was set to be 100-1000 ppm. Just after sulfidation, the coils temperature was optimized to be 825-836 ${ }^{\circ} \mathrm{C}$ and the steam flow was co-injected.

Ethane feed along with dilution water steam and DMDS was injected into the tubular reactor leading to gradual formation of catalytic coke layer on the inside surface of the tubes. In the cracking temperature $\left(800-820^{\circ} \mathrm{C}\right)$, the transition metals are self-diffused into the produced coke. The behavior of catalytic coke shows that a filamentous morphology and $\mathrm{Fe}, \mathrm{Ni}$ and $\mathrm{Cr}$ from the metal matrix of the reactor walls diffuse into the filaments coke matrix (Reyniers et al. 1994). For the consideration of energy saving, the cooling water was directed to a steam boiler as boiler feed water (BFW) for production of dilution steam. After increasing the coke thickness and reducing the interior diameter of tubular reactor, the furnace was switched to the decoking stage, at which the cylindrical catalytic coke was separated from the tubular reactor by steam and air injection at hot temperatures $\left(810-850^{\circ} \mathrm{C}\right)$. Figure 1 shows a schematic of ethane cracker furnaces, their flow diagrams and the tubular reactor direction.

\subsection{Graphitization of the catalytic coke}

The cylindrical samples of catalytic coke were milled and sieved in the particle range of $0.1-1.0 \mathrm{~mm}$. The calcination of coke breeze was performed in a reactor embedded in box furnace (REBF) under controlled atmosphere, temperature and time. The calcination of catalytic coke breeze were carried out in different conditions including $\mathrm{N}_{2}$, water steam, air and $\mathrm{CO}_{2}$ atmospheres, the temperatures of $850{ }^{\circ} \mathrm{C}, \quad 1050{ }^{\circ} \mathrm{C}, \quad 1350{ }^{\circ} \mathrm{C}$ and $1470{ }^{\circ} \mathrm{C}$, temperature ramps of $5,10,15$ and $20^{\circ} \mathrm{C} / \mathrm{min}$, the range of sulfur content $0 \%-1.0 \%, 1.0 \%-2.0 \%, 2.0 \%-3.0 \%$ and $3.0 \%-4.0 \%$ wt. and the heating times of 1, 30, 60 and $120 \mathrm{~min}$. The REBF was filled by ceramic balls $(3 \mathrm{~mm}$ and $10 \mathrm{~mm}$ in diameter) as the supporting material and the catalytic coke breeze was filled and packed as presented in 
Fig. 2. The controlled atmosphere was flowed and exhausted from the sides of REBF. The ceramic balls not only improved the gas flow distribution but also prevented the choking tendency of fine particles in the exhaust line.

The calcination was designed by Taguchi algorithm and the above-mentioned parameters (five items), each of them at four different levels, were optimized. Table 1 shows the examined parameters and the relevant levels. The agglomeration runs were designed according to design of experiments (DoE) methodology, based upon 6 terms of aromaticity $(f)$, coke rank $(\mathrm{CR}), \mathrm{L}_{\mathrm{a}}, \mathrm{L}_{\mathrm{c}}$, graphitization degree $(g)$ and the number of carbon rings per lamella $(N)$, respectively.

\subsection{Determination of electrical resistivity}

The electrical resistivity was evaluated using a microohmmeter and the four-point soil box adopted for this application. The electrical current was applied between the outer-pins while the voltage was monitored between the inner-pins. The electrical resistance was determined by the appropriate values of electrical current and the voltagedrop was measured between the inner-pins.

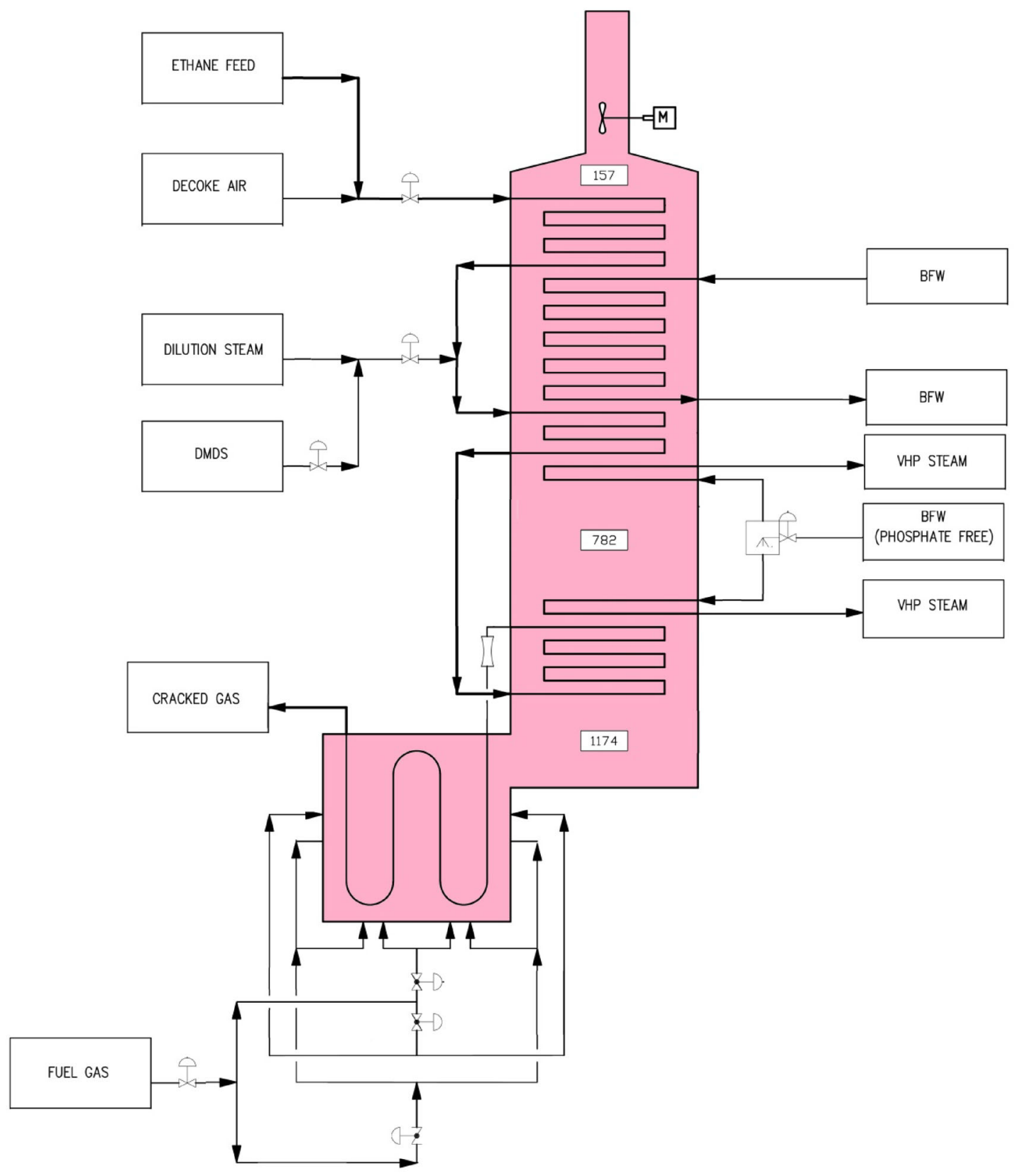

Fig. 1 Schematic representation of ethane cracker furnace for production of self-diffused catalytic coke 
Table 1 The controlled parameters in $\mathrm{L}_{16}$ orthogonal-array at different levels

\begin{tabular}{llllll}
\hline Parameters & Symbols & $\mathrm{L}_{1}$ & $\mathrm{~L}_{2}$ & $\mathrm{~L}_{3}$ & $\mathrm{~L}_{4}$ \\
\hline Atmosphere & $\mathrm{P}_{1}$ & $\mathrm{~N}_{2}$ & Water steam & $\mathrm{CO}_{2}$ \\
Temperature $\left({ }^{\circ} \mathrm{C}\right)$ & $\mathrm{P}_{2}$ & 850 & 1050 & 1350 & 1470 \\
Temperature ramp $\left({ }^{\circ} \mathrm{C} / \mathrm{min}\right)$ & $\mathrm{P}_{3}$ & 5 & 10 & 15 & 20 \\
Sulfur content $(\mathrm{wt} \%)$ & $\mathrm{P}_{4}$ & $0-1.0$ & $1.0-2.0$ & $2.0-3.0$ & $3.0-4.0$ \\
Heating time $(\mathrm{min})$ & $\mathrm{P}_{5}$ & 1 & 30 & 60 \\
\hline
\end{tabular}

\section{Results and discussions}

The investigated parameters on the graphite samples include $f$-value, $\mathrm{CR}, \mathrm{L}_{\mathrm{a}}, \mathrm{L}_{\mathrm{c}}, g$ and $N$, which were determined by pattern recognition of XRD signals (Fig. 3). The signals include $\gamma\left(17^{\circ}\right), 002\left(26^{\circ}\right), 100\left(42^{\circ}\right), 101\left(43^{\circ}\right), 004$ $\left(53^{\circ}\right), 103\left(59^{\circ}\right)$ and $110\left(78^{\circ}\right)$ in the range of $2 \theta=5^{\circ}-$

$80^{\circ}$. By improving the graphitization degree, the shape and the situation of XRD signals are varied leading to orientation of the carbon scaffold. The step size and scanning rate of XRD tests were fixed to be 0.02 degrees 2-theta and $10 \%$ min, respectively.

The strength of signals $(I)$, the area behind them $(A)$, the full width at half maximum (FWHM, $B$ ) and the angle of signal $(\varphi)$ are the key elements to formulate the graphitization process of cracked cokes. The subscripts $a$ and $c$ are corresponded to (100) and (002) peaks, respectively. Table 2 shows the above-listed parameters for two distinct signals that have been obtained during the pre-designed experiments. Figure 4 shows the XRD patterns of all the samples.

ASTM D5187 covers the determination of the mean crystallite thickness of coke samples by XRD patterns that are obtained by conventional X-ray scanning instruments. The XRD pattern was obtained in the range of $5^{\circ}-85^{\circ} 2 \theta$ using $\mathrm{Cu}$ tube $(\lambda=1.54 \AA)$ and $R_{1-6}$ are determined by Eq. 1 to Eq. 7.

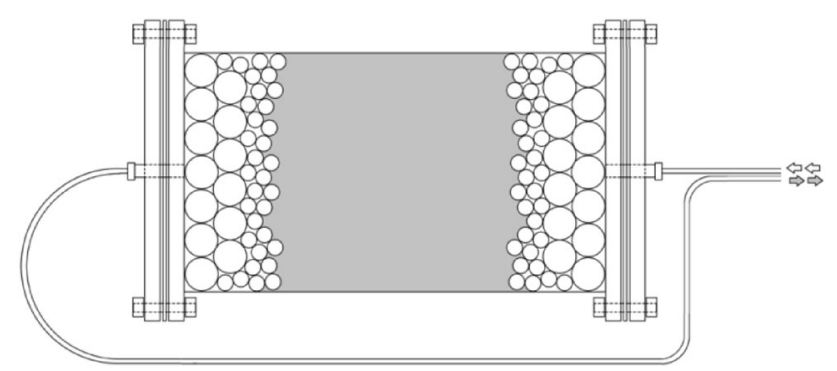

Fig. 2 Graphical implementation of REBF filled by ceramic balls and catalytic coke
$f=\frac{C_{a r}}{C_{a r}+C_{a l}}=\frac{A_{002}}{A_{002}+A_{\gamma}}$

$C R=\frac{I_{26}}{I_{20}}$

$L_{a}=\frac{1.84 \lambda}{B_{a} \cos \varphi_{a}}$

$L_{c}=\frac{0.89 \lambda}{B_{c} \cos \varphi_{c}}$

$d_{002}=\frac{n \lambda}{\sin \varphi_{c}}$

$g=\frac{3.44-d_{002}}{0.086}$

$N=\frac{L_{c}+d_{002}}{d_{002}}$

where in Eq. 1, $\mathrm{C}_{\mathrm{ar}}$ and $\mathrm{C}_{\mathrm{al}}$ show the number of aromatic and aliphatic carbons ( $\mathrm{Lu}$ et al. 2001; Odeh 2015), respectively. Likewise, $A_{002}$ and $A_{\gamma}$ represent the integrated area under the corresponding peaks $002\left(2 \theta=26.7^{\circ}\right)$ and $\gamma$ $\left(2 \theta=17^{\circ}-20^{\circ}\right)$, respectively. On the other hand, in Eq. 2, $I_{26}$ and $I_{20}$ reveal the peaks intensity at positions $2 \theta=20^{\circ}$ and $2 \theta=26^{\circ}$, respectively. In Eqs. 3 and $4, B$ and $\varphi$ show the half width of peaks ( $2 \theta$, radians) and the corresponding

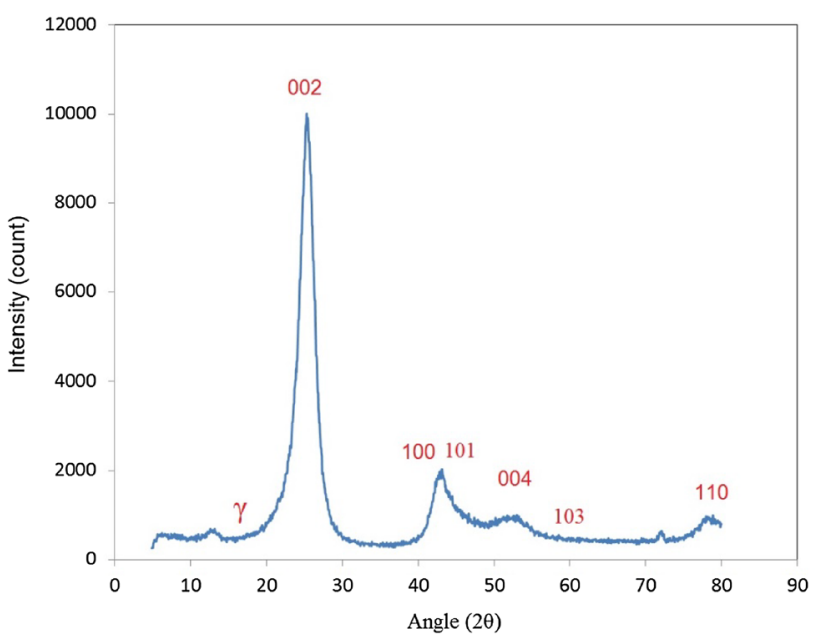

Fig. 3 XRD pattern of un-graphitized coke 
Table 2 The results of XRD readouts for the designed experiments

\begin{tabular}{|c|c|c|c|c|c|c|c|c|}
\hline Run & $A_{002}$ (counts- $\left.2 \theta\right)$ & $A_{\gamma}($ counts $-2 \theta)$ & $I_{26}$ (counts) & $I_{20}$ (counts) & $B_{\mathrm{a}}(\mathrm{rad})$ & $B_{\mathrm{c}}(\mathrm{rad})$ & $\varphi_{\mathrm{a}}\left({ }^{\circ}\right)$ & $\varphi_{\mathrm{c}}\left({ }^{\circ}\right)$ \\
\hline 1 & 40100 & 479 & 8020 & 652 & 0.0065 & 0.0045 & 20.95 & 13.20 \\
\hline 2 & 39800 & 502 & 7990 & 652 & 0.0065 & 0.0043 & 20.9 & 13.20 \\
\hline 3 & 50150 & 489 & 10010 & 713 & 0.0063 & 0.0034 & 20.95 & 13.25 \\
\hline 4 & 45000 & 491 & 9020 & 719 & 0.005 & 0.0041 & 20.9 & 13.24 \\
\hline 5 & 4800 & 520 & 990 & 688 & 0.0174 & 0.0175 & 20.5 & 12.94 \\
\hline 6 & 10100 & 492 & 2030 & 689 & 0.0162 & 0.0172 & 20.5 & 12.96 \\
\hline 7 & 9980 & 490 & 2000 & 700 & 0.0154 & 0.0155 & 20.55 & 12.97 \\
\hline 8 & 14400 & 492 & 2890 & 650 & 0.0128 & 0.0148 & 20.65 & 13.00 \\
\hline 9 & 29950 & 478 & 5980 & 702 & 0.0109 & 0.0093 & 20.75 & 13.09 \\
\hline 10 & 30100 & 520 & 6050 & 699 & 0.0108 & 0.0091 & 20.8 & 13.11 \\
\hline 11 & 41000 & 552 & 8100 & 629 & 0.0085 & 0.0065 & 20.85 & 13.18 \\
\hline 12 & 36000 & 551 & 7210 & 791 & 0.0092 & 0.0081 & 20.85 & 13.16 \\
\hline 13 & 14400 & 539 & 2890 & 681 & 0.0133 & 0.0139 & 20.6 & 13.01 \\
\hline 14 & 20500 & 589 & 4120 & 680 & 0.0119 & 0.0107 & 20.7 & 13.06 \\
\hline 15 & 24400 & 522 & 4900 & 640 & 0.0101 & 0.0095 & 20.7 & 13.08 \\
\hline 16 & 30300 & 520 & 6070 & 641 & 0.0101 & 0.0087 & 20.75 & 13.10 \\
\hline
\end{tabular}

12000

0

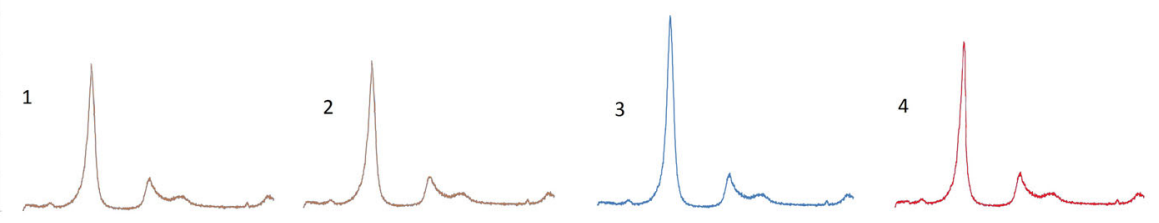

6000
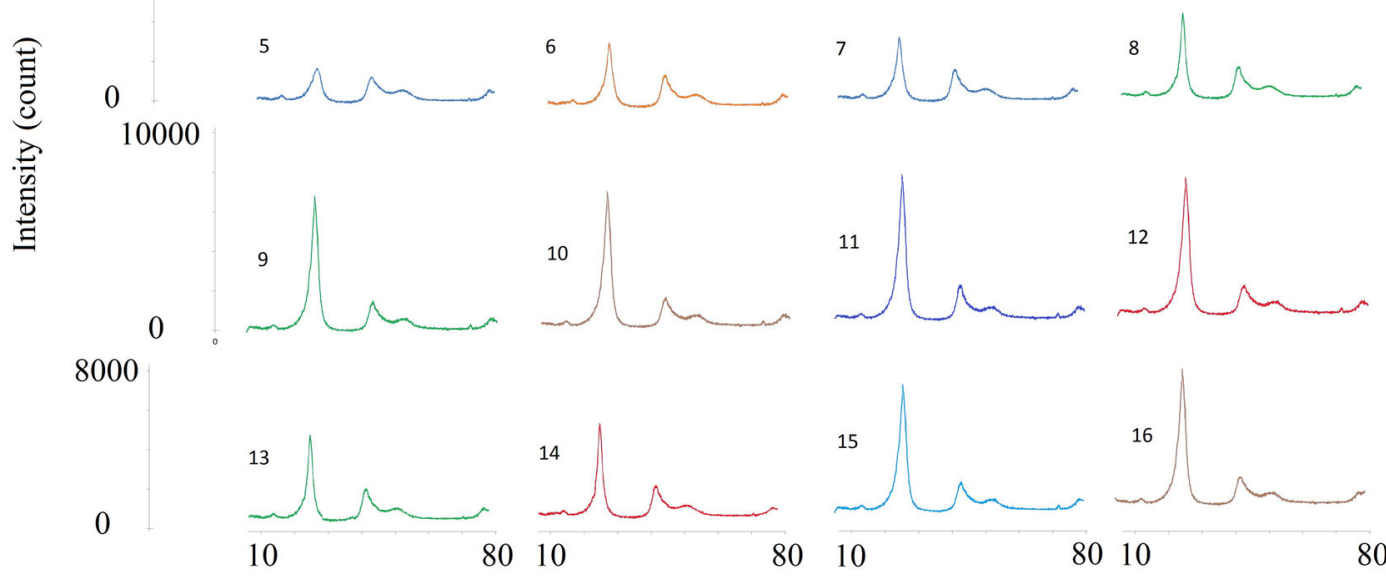

Angle (20)

Fig. 4 XRD patterns of all the samples

scattering angles $(\theta$, degree), respectively. The subscript signs $a$ and $c$ are corresponded to (100) and (002) peaks, respectively. $d_{002}$ in bragg's equation (Eq. 5) exhibits the interlayer spacing, in which $n$ is a positive integer and $\lambda$ is the wavelength of the incident wave $(\mathrm{Cu}, 1.54 \AA)$.

Therefore, all of 6 responses $\left(R_{1}\right.$ to $\left.R_{6}\right)$ are controlled by eight readouts obtained from the XRD patterns of 
individual coke and graphite samples that were produced from run 1 to run 16. According to Eqs. 1-6, these readouts are including $A_{002}, A_{\gamma}, I_{26}, I_{20}, B_{\mathrm{a}}, B_{\mathrm{c}}, \varphi_{\mathrm{a}}$ and $\varphi_{\mathrm{c}}$. The next section reveals the results of XRD experiments representing the above-listed readouts.

In Table 3, the terms of $R_{1-6}$ reveal the responses obtained by XRD patterns of graphitized coke samples, which has been used for the determination of coke crystallinity including $f$-value, $\mathrm{CR}, \mathrm{L}_{\mathrm{a}}, \mathrm{L}_{\mathrm{c}}, g$ and $N$.

The results of Taguchi algorithm revealed that among five parameters, the atmosphere composition strongly affected the graphitization efficiency. Increasing the maximum temperature from 850 to $1470{ }^{\circ} \mathrm{C}$ as well as the exposure time of thermal operation from 0 to $120 \mathrm{~h}$ led to the improvement of the graphitization of catalytic coke. Likewise, the temperature ramp of $15{ }^{\circ} \mathrm{C} / \mathrm{min}$ and sulfur content range of $1 \%-2 \%$ wt. revealed the other optimum conditions. Figure 5 shows the graphical implementation of Taguchi response by five parameters and four levels.

\subsection{Effect of graphitization atmosphere}

As presented in Fig. 5, the gasification (water-gas shift) reaction by water steam and $\mathrm{CO}_{2}$ (Chianese et al. 2015) has decreased the graphitization efficiency of ethane-based catalytic coke. The experimental results revealed that water steam decreases the graphitization efficiency of ethanebased catalytic coke. Water steam loses the coke structure, leading to the increasing of the structural damage of

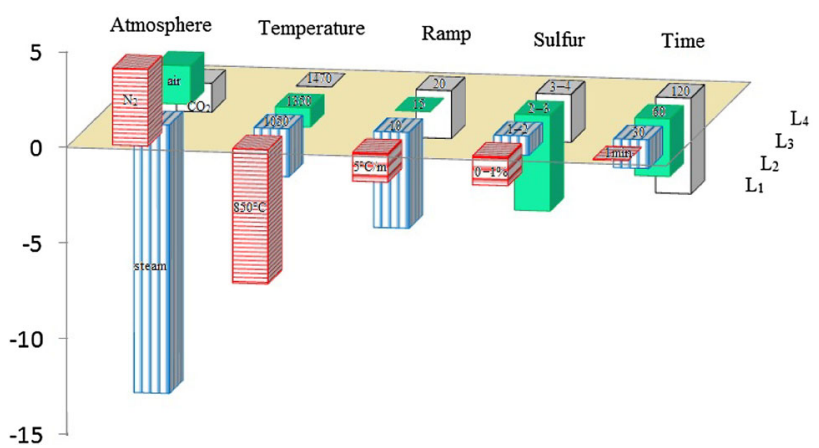

Fig. 5 Schematic illustration of Taguchi response for graphiteoptimization of catalytic coke

polycyclic planes of catalytic coke. This damage is the main cause of micro-fractures in the body of deposited coke used in decoking operation of gas crackers of refineries. At high temperatures, the thermal decomposition of water steam on the carbon surfaces helped form active hydrogen atoms that are responsible for ring opening of polycyclic aromatic scaffolds of coke matrix and the decreasing of the graphite properties. On the other hand, $\mathrm{CO}_{2}$ atmosphere limits the graphitization phenomena of catalytic coke because of the enhancement of the gasification process.

It was demonstrated that aforementioned $\mathrm{Cr}$ (Chianese et al. 2015), Ni (Zhao et al. 2014; Guo et al. 2015) and Fe (Chianese et al. 2015) dopants preset in the matrix of catalytic coke catalyze the gasification reactions under water steam and $\mathrm{CO}_{2}$ atmospheres. The unique

Table 3 The run test characteristics

\begin{tabular}{|c|c|c|c|c|c|c|c|c|c|c|c|}
\hline \multirow[t]{2}{*}{ Run } & \multicolumn{5}{|l|}{ Parameters } & \multicolumn{6}{|c|}{ Responses } \\
\hline & $\mathrm{P}_{1}$ & $\mathrm{P}_{2}$ & $\mathrm{P}_{3}$ & $\mathrm{P}_{4}$ & $\mathrm{P}_{5}$ & $R_{1}$ & $R_{2}$ & $R_{3}$ & $R_{4}$ & $R_{5}$ & $R_{6}$ \\
\hline 1 & $\mathrm{~N}_{2}$ & 850 & 5 & $0-1.0$ & 1 & 0.99 & 12.3 & 467 & 313 & 0.79 & 94 \\
\hline 2 & $\mathrm{~N}_{2}$ & 1050 & 10 & $1.0-2.0$ & 30 & 0.99 & 12.3 & 467 & 327 & 0.79 & 98 \\
\hline 3 & $\mathrm{~N}_{2}$ & 1350 & 15 & $2.0-3.0$ & 60 & 0.99 & 14.0 & 482 & 414 & 0.94 & 124 \\
\hline 4 & $\mathrm{~N}_{2}$ & 1470 & 20 & $3.0-4.0$ & 120 & 0.99 & 12.5 & 607 & 343 & 0.91 & 103 \\
\hline 5 & Water steam & 850 & 10 & $2.0-3.0$ & 120 & 0.90 & 1.4 & 174 & 80 & 0.02 & 24 \\
\hline 6 & Water steam & 1050 & 5 & $3.0-4.0$ & 60 & 0.95 & 2.9 & 187 & 82 & 0.08 & 25 \\
\hline 7 & Water steam & 1350 & 20 & $0-1.0$ & 30 & 0.95 & 2.9 & 197 & 91 & 0.11 & 27 \\
\hline 8 & Water steam & 1470 & 15 & $1.0-2.0$ & 1 & 0.97 & 4.4 & 237 & 95 & 0.20 & 29 \\
\hline 9 & Air & 850 & 15 & $3.0-4.0$ & 30 & 0.98 & 8.5 & 278 & 151 & 0.47 & 46 \\
\hline 10 & Air & 1050 & 20 & $2.0-3.0$ & 1 & 0.98 & 8.7 & 281 & 155 & 0.53 & 47 \\
\hline 11 & Air & 1350 & 5 & $1.0-2.0$ & 120 & 0.99 & 12.9 & 357 & 217 & 0.73 & 65 \\
\hline 12 & Air & 1470 & 10 & $0-1.0$ & 60 & 0.98 & 9.1 & 330 & 174 & 0.67 & 52 \\
\hline 13 & $\mathrm{CO}_{2}$ & 850 & 20 & $1.0-2.0$ & 60 & 0.96 & 4.2 & 228 & 101 & 0.23 & 31 \\
\hline 14 & $\mathrm{CO}_{2}$ & 1050 & 15 & $0-1.0$ & 120 & 0.97 & 6.1 & 255 & 131 & 0.38 & 40 \\
\hline 15 & $\mathrm{CO}_{2}$ & 1350 & 10 & $3.0-4.0$ & 1 & 0.98 & 7.7 & 300 & 148 & 0.44 & 45 \\
\hline 16 & $\mathrm{CO}_{2}$ & 1470 & 5 & $2.0-3.0$ & 30 & 0.98 & 9.5 & 300 & 162 & 0.50 & 49 \\
\hline
\end{tabular}


thermophysical properties of $\mathrm{H}_{2} \mathrm{O}$ and $\mathrm{CO}_{2}$ are responsible for distinct reactions of catalytic coke under gasification process (Hwang et al. 2011; Zhu and Wachs 2015) as Eqs. 8-10 explain:

$$
\begin{aligned}
& \mathrm{CO}_{2}(g)+\mathrm{C}(s) \rightarrow 2 \mathrm{CO}(g) \\
& \mathrm{H}_{2} \mathrm{O}(\mathrm{g})+\mathrm{C}(s) \rightarrow \mathrm{CO}(g)+\mathrm{H}_{2}(g) \\
& \mathrm{H}_{2} \mathrm{O}(\mathrm{g})+\mathrm{CO}(\mathrm{g}) \rightarrow \mathrm{CO}_{2}(g)+\mathrm{H}_{2}(g)
\end{aligned}
$$

In air atmosphere, the burning process of catalytic coke was carried out, activating rings opening of polycyclic aromatics and losing the graphite planes at annealing conditions, while under nitrogen atmosphere none of the gasification and burning reactions was carried out to improve the graphitization process at the temperatures of interest.

\subsection{Effect of graphitization temperature}

While some carbon-substrates attain ordered orientation at temperatures below $2000{ }^{\circ} \mathrm{C}$, the other carbonaceous materials do not exhibit such ordered scaffold even above $3000{ }^{\circ} \mathrm{C}$. Therefore, the graphitization reactions also depend on the scaffold of the materials being graphitized (Gupta et al. 2017). On the other hand, carbon graphitization at relatively low temperatures (below $1500{ }^{\circ} \mathrm{C}$ ) has been assessed by low dosage injection of some transition metals (such as Fe, Ni and Mn) (Sevilla and Fuertes 2006; Barbera et al. 2014) as the scope of the present study.

The effect of graphitization temperature was assessed in the range of $850-1470{ }^{\circ} \mathrm{C}$ and the results showed that the graphitization was enhanced at high temperatures up to $1470{ }^{\circ} \mathrm{C}$, at which the structural modifications of polycyclic scaffolds were occurred and more desulfidation was performed. High temperature desulfurization is discussed in the next section. Figure 6 shows the effect of maximum temperature on the graphitization degree of catalytic coke, schematically.

The coke samples were graphitized at $850{ }^{\circ} \mathrm{C}$ showing a broad signal at $26^{\circ} 2 \theta(002)$ along with a shoulder at $42^{\circ} 2 \theta$ (100). By increasing the temperature of graphitization to
$1050{ }^{\circ} \mathrm{C}$ the broad signal was split into three segments having signal centers at $23^{\circ} 2 \theta, 26^{\circ} 2 \theta$ and at $31^{\circ} 2 \theta$. The middle signal was sharp $\left(\mathrm{FWHM}=3.43^{\circ}\right)$ at $2 \theta$ value closer to the anticipated 002 signal of graphite. Upon further increase in temperature to $1350{ }^{\circ} \mathrm{C}$, this signal was further narrowed $\left(\mathrm{FWHM}=2.43^{\circ}\right)$. Reduction of signal width was continued when the temperature was increased to $1470{ }^{\circ} \mathrm{C}$. The middle signal at $26^{\circ} 2 \theta$ was further narrowed $\left(\mathrm{FWHM}=2.03^{\circ}\right)$. Decreasing of signal width along with increasing the graphitization temperature reveals the increasing of $s p 2$-bonded content in the coke matrices.

When the metal-impregnated catalytic coke is heattreated under nitrogen atmosphere, the metallic species are reduced from the metal oxide to the elemental metal (e.g. $\mathrm{Fe}$ and Ni). At temperatures higher than $800{ }^{\circ} \mathrm{C}$, the selfdiffused metallic particle contained within the coke media acted as catalyst for the conversion of amorphous-carbon to more ordered graphitic-carbon. The type of doped metal has a great role in the graphitization of coke samples. In this regard, Sevilla and Fuertes (Sevilla and Fuertes 2006) studied the effect of three metals on the graphitization degree and they proposed the following order: $\mathrm{Ni}>\mathrm{Mn}>\mathrm{Fe}$.

\subsection{Effect of temperature ramp and sulfur content}

The samples of petroleum coke were normally calcined up to $1400{ }^{\circ} \mathrm{C}$ and desulfurization was carried out to a significant degree within this temperature range. However, the desulfurization efficiency was not only dependent on the applied temperature, but also was affected by other parameters including the heating ramp, residence time, gas blanket atmosphere and the concentration of catalytic metals. Thermal desulfurization of catalytic coke was conducted along with the graphitization reaction, simultaneously and it is divided into four phases as the following (Al-Haj-Ibrahim and Morsi 1992).

(1) Initial phase of desulfurization $\left(850^{\circ} \mathrm{C}\right)$
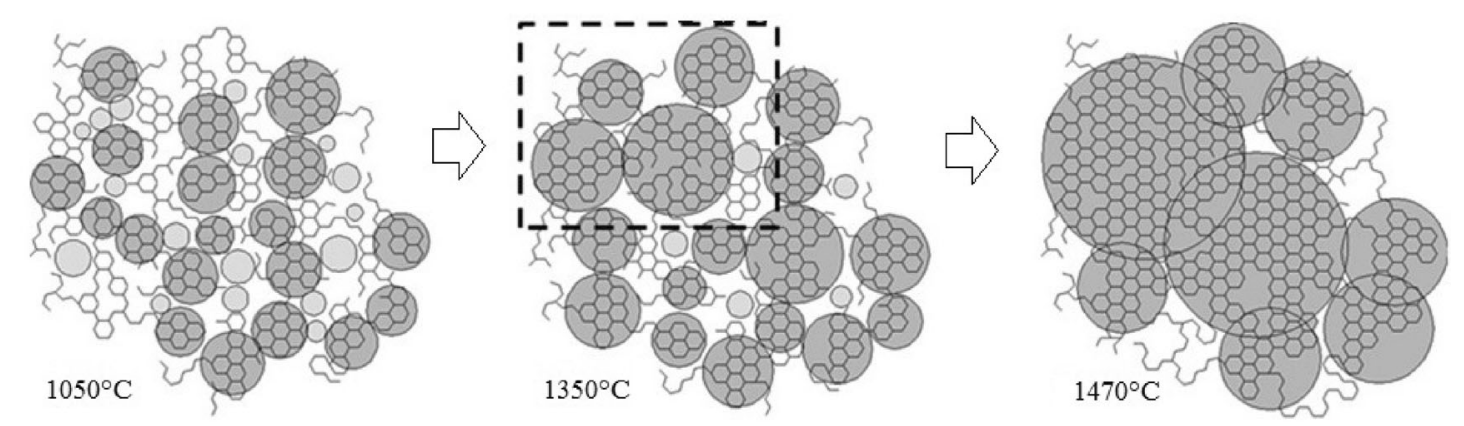

Fig. 6 Graphical implementation of graphitization degree versus heating temperature 
The sulfur bounds on the surfaces or in the matrix pores are broken and simultaneously the side chains of aromatic molecules are cracked. The maximum amounts of sulfur removed in this phase are reported to be less than $25 \%$ since no reaction takes place between sulfur and metals and no variation is observed in desulfurization degree of catalytic cokes with self-diffused metals.

(2) Second phase of desulfurization $\left(1050{ }^{\circ} \mathrm{C}\right)$

In this phase, little or no desulfurization is performed as it is significantly depressed by the self-diffused metals (e.g. $\mathrm{Ni}$ ) that react with dissociated-sulfurs to form refractorysulfur. Ash and self-diffused metals seem to have no effect on desulfurization up to this temperature, while at temperatures greater than or equal to $1050{ }^{\circ} \mathrm{C}$ desulfurization is further inhibited by forming a thermally stable metalsulfide.

(3) Third phase of desulfurization $\left(1350{ }^{\circ} \mathrm{C}\right)$

Upon further increase in temperature of catalytic coke to $1350{ }^{\circ} \mathrm{C}$, the available energy is enough high for the decomposition of sulfur-hydrocarbon compounds such as thiophenes. In this phase it is not possible to eliminate total sulfur from the coke matrix since the desulfurization degree is significantly related to total sulfur content of the coke.

(4) Third phase of desulfurization $\left(1470{ }^{\circ} \mathrm{C}\right)$

Further increase in temperature cannot lead to more desulfurization, since it depends mainly on the nature of coke. In this phase, the apparent density of catalytic coke was increased from $1.3( \pm 0.1)$ to $1.8( \pm 0.2)$. In this temperature range, the density change depends on the initial sulfur-content. In the presence of high sulfur-content cokes, the coke density was decreased; and with coke samples of low sulfur-content, the density was increased. The decrease of apparent density at $1470{ }^{\circ} \mathrm{C}$, which is called the puffing phenomenon, is the result of porosity development when the sulfur-species get out from the coke media.

\subsection{Effect of heating time}

Abdul Abas et al. (Abas et al. 2006) studied the graphitization of blast furnace coke and they reported that the graphitization degree is independent from time. However the results of the present study revealed that the graphitization criteria of catalytic coke are declined by increasing the exposure time. This may be due to the high surface energy of the coke, which intensifies the time-dependent puffing phenomena at elevated temperatures. The porosity development of the aged samples of heat-treated coke leads to decreasing the graphitization criteria.

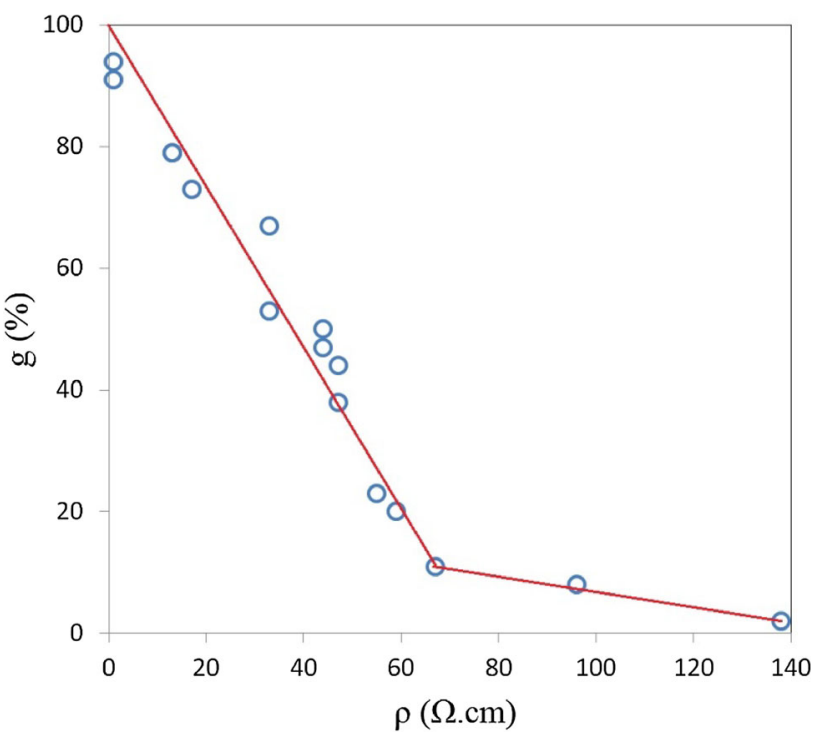

Fig. 7 Linear dependency of g vs. $\rho$ for the graphitized samples of ethane-based coke

\subsection{Electrical resistivity}

The success of catalytic graphitization can be assessed by a notable improvement in the electrical resistivity $(\rho)$ (Sevilla and Fuertes 2006). The electrical resistivity of graphitized coke samples depends mainly on the atmosphere, the exposure time and the temperature employed. Figure 7 shows the linear dependency of $\rho$ to $g$, representing a threshold point at $g=10 \%$ and $\rho=65 \Omega . \mathrm{cm}$.

\subsection{Determination of transition metals}

Coke formation in tubular reactors is a steady state process, which takes place in long periods of time, in the range of several days. At enough high temperatures, iron and nickel elements diffuse into the coke matrix along with chromium migration leading to formation of a ferromagnetic coke. Distribution of the above-mentioned elements in the coke matrix was studied by EDX-mapping (Tsuneta et al. 2002; Allen et al. 2012) and the results revealed that the concentration of the diffused elements is reduced from the exterior surface to the inner surface of coke layer. On the other hand, the concentration of sulfur-containing compounds was studied along the thickness of the coke layer by EDX-mapping and the results revealed that sulfur concentration is increased from the outer to the inner surface. Figure 8 shows a schematic representation of metal and sulfur distribution in the coke matrix. 


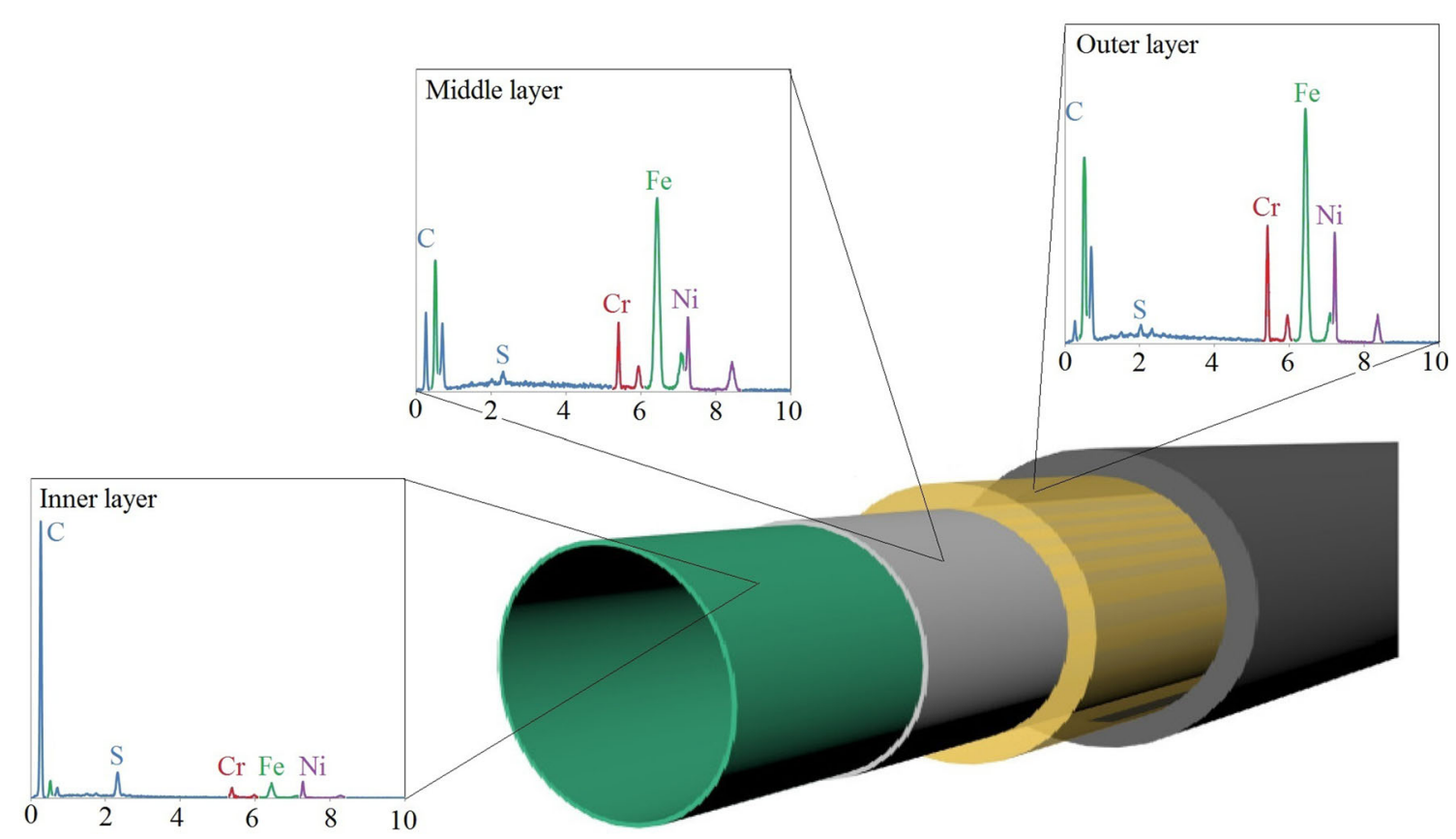

Fig. 8 EDX-mapping of the deposited coke on the inner surfaces of tubular reactor

\section{Conclusions}

(1) Self-diffusion of some structural metals into the coke matrix varies their reactivity and their responses in thermal operations.

(2) The blanket atmosphere, final temperature and exposure time showed a remarkable effect on the aforementioned criteria, while the role of thermal ramp and sulfur content of catalytic coke was negligible.

(3) The gasification reaction by water steam and $\mathrm{CO}_{2}$ leads to decrease the graphitization efficiency of ethane-based catalytic coke. On the other hand, in air atmosphere, the burning process of catalytic coke causes the rings opening of polycyclic aromatics and losing the graphite planes at annealing conditions. Under nitrogen atmosphere, none of the gasification and burning reactions was carried out leading to improve the graphitization process at the temperatures of interest.

(4) At elevated temperatures, the high surface energy of coke samples intensifies the time-dependent puffing phenomena leading to porosity development of the aged samples and decreasing the graphitization criteria.

Open Access This article is distributed under the terms of the Creative Commons Attribution 4.0 International License (http://crea tivecommons.org/licenses/by/4.0/), which permits unrestricted use, distribution, and reproduction in any medium, provided you give appropriate credit to the original author(s) and the source, provide a link to the Creative Commons license, and indicate if changes were made.

\section{References}

Abas RA, Jakobsson A, Hayashi M, Seetharaman S (2006) Studies on graphitisation of blast furnace coke by $\mathrm{x}$-ray diffraction analysis and thermal diffusivity measurements. Steel Res Int 77:763-769

Al-Haj-Ibrahim H, Morsi BI (1992) Desulfurization of petroleum coke: a review. Ind Eng Chem Res 31:1835-1840

Allen LJ, D'Alfonso AJ, Freitag B, Klenov DO (2012) Chemical mapping at atomic resolution using energy-dispersive $\mathrm{x}$-ray spectroscopy. MRS Bull 37:47-52

Anton R (2005) In situ transmission electron microscopy study of the growth of $\mathrm{Ni}$ nanoparticles on amorphous carbon and of the graphitization of the support in the presence of hydrogen. J Mater Res 20:1837-1843

Anton $\mathrm{R}$ (2008) On the reaction kinetics of $\mathrm{Ni}$ with amorphous carbon. Carbon N Y 46:656-662

Anton R (2009) In situ TEM investigations of reactions of Ni, Fe and $\mathrm{Fe}-\mathrm{Ni}$ alloy particles and their oxides with amorphous carbon. Carbon N Y 47:856-865

Barbera K, Frusteri L, Italiano G et al (2014) Low-temperature graphitization of amorphous carbon nanospheres. Chin J Catal $35: 869-876$

Belenkov EA (2001) Formation of graphite structure in carbon crystallites. Inorg Mater 37:928-934

Bokhonov B, Korchagin M (2002) The formation of graphite encapsulated metal nanoparticles during mechanical activation and annealing of soot with iron and nickel. J Alloys Compd 333:308-320

Carter LM, Brockman JD, Loyalka SK, Robertson JD (2015) Measurement of cesium diffusion coefficients in graphite IG110. J Nucl Mater 460:30-36

Chianese S, Loipersböck J, Malits M et al (2015) Hydrogen from the high temperature water gas shift reaction with an industrial $\mathrm{Fe} / \mathrm{Cr}$ 
catalyst using biomass gasification tar rich synthesis gas. Fuel Process Technol 132:39-48

De Jong KP, Geus JW (2000) Carbon nanofibers: catalytic synthesis and applications. Catal Rev 42:481-510

Feng B, Bhatia SK, Barry JC (2003) Variation of the crystalline structure of coal char during gasification. Energy Fuels $17: 744-754$

Feret FR (1998) Determination of the crystallinity of calcined and graphitic cokes by X-ray diffraction. Analyst 123:595-600

Guo W, Xue Q, Liu Y et al (2015) Kinetic analysis of gasification reaction of coke with $\mathrm{CO} 2$ or $\mathrm{H} 2 \mathrm{O}$. Int $\mathrm{J}$ Hydrogen Energy 40:13306-13313

Gupta S, Sahajwalla V, Chaubal P, Youmans T (2005) Carbon structure of coke at high temperatures and its influence on coke fines in blast furnace dust. Metall Mater Trans B 36:385-394

Gupta A, Dhakate SR, Pal P et al (2017) Effect of graphitization temperature on structure and electrical conductivity of polyacrylonitrile based carbon fibers. Diam Relat Mater 78:31-38

Helveg S, López-Cartes C, Sehested J et al (2004) Atomic-scale imaging of carbon nanofibre growth. Nature 427:426

Hennig G (1965) Diffusion of boron in graphite. J Chem Phys 42:1167-1172

Hwang K-R, Lee C-B, Park J-S (2011) Advanced nickel metal catalyst for water-gas shift reaction. J Power Sources 196:1349-1352

Li K, Khanna R, Zhang J et al (2014) The evolution of structural order, microstructure and mineral matter of metallurgical coke in a blast furnace: a review. Fuel 133:194-215

Loch LD, Gambino JR, Duckworth WH (1956) Diffusion of uranium through graphite. AIChE J 2:195-198

Lu L, Sahajwalla V, Kong C, Harris D (2001) Quantitative X-ray diffraction analysis and its application to various coals. Carbon N Y 39:1821-1833

Mollick PK, Venugopalan R, Roy M et al (2015) Deposition of diversely textured buffer pyrolytic carbon layer in TRISO coated particle by controlled manipulation of spouted bed hydrodynamics. Chem Eng Sci 128:44-53

Odeh AO (2015) Comparative study of the aromaticity of the coal structure during the char formation process under both conventional and advanced analytical techniques. Energy Fuels 29:2676-2684

Pourabdollah K (2017a) Process design of matrix acidizing by antifouling agents. Chem Eng Res Des 121:407-420
Pourabdollah K (2017b) Development of electrolyte inhibitors in nickel cadmium batteries. Chem Eng Sci 160:304-312

Pourabdollah K (2018a) Self-assembled monolayers, the agglomeration binders of pyrolytic coke fines. Powder Technol 339:130-138

Pourabdollah K (2018b) Process design of cyclic water flooding by real-time monitoring. J Energy Resour Technol 140:112701

Reyniers GC, Froment GF, Kopinke F-D, Zimmermann G (1994) Coke formation in the thermal cracking of hydrocarbons. 4. Modeling of coke formation in naphtha cracking. Ind Eng Chem Res 33:2584-2590

Sevilla M, Fuertes AB (2006) Catalytic graphitization of templated mesoporous carbons. Carbon N Y 44:468-474

Shigeno Y, Kobayashi S, Omori Y (1988) High temperature measurement of the effective diffusivity through coke and graphite by the Wicke-Kallenbach method. Trans Iron Steel Inst Jpn 28:697-704

Sonibare OO, Haeger T, Foley SF (2010) Structural characterization of Nigerian coals by X-ray diffraction, Raman and FTIR spectroscopy. Energy 35:5347-5353

Stoneham AM (1979) The motions of iron particles on graphite. Appl Surf Sci 3:161-167

Tsuneta R, Koguchi M, Nakamura K, Nishida A (2002) A specimendrift-free EDX mapping system in a STEM for observing twodimensional profiles of low dose elements in fine semiconductor devices. J Electron Microsc (Tokyo) 51:167-171

Wang R, Lu G, Qiao W, Yu J (2016) Catalytic graphitization of coalbased carbon materials with light rare earth elements. Langmuir 32:8583-8592

Wissler M (2006) Graphite and carbon powders for electrochemical applications. J Power Sour 156:142-150

Yoshizawa N, Maruyama K, Yamada Y et al (2001) Standardization of carbon structural analysis in coal by $\mathrm{X}$-ray diffraction (1)influence of deashing and solvent treatment upon stacking structure of aromatic layers in coal. J Jpn Inst Energy 80:349-355

Zhao F, Liu Z, Xu W et al (2014) Water-gas shift reaction on Ni-WCe catalysts: catalytic activity and structural characterization. J Phys Chem C 118:2528-2538

Zhu M, Wachs IE (2015) Iron-based catalysts for the high-temperature water-gas shift (HT-WGS) reaction: a review. ACS Catal $6: 722-732$ 